Artigos 


\section{La experiencia corpórea de enfermedad: un abordaje desde la fenomenología de Merleau-Ponty}

\section{The corporeal experience of illness: an approach from the Merleau-Ponty phenomenology}

DOI: $10.12957 /$ ek.2018.33855

Prof $^{a}$. Dra ${ }^{\mathrm{a}}$. Leila Martina Passerino leilapasse@hotmail.com

Universidad de Buenos Aires, Argentina

El artículo reflexiona en torno a la experiencia de la enfermedad desde la fenomenología de Merleau-Ponty. Experiencia del orden de lo disruptivo, que introduce la dimensión de la inhabitualidad, la enfermedad se asume como reconfiguración necesaria del esquema corporal. En el marco de una investigación acerca de la experiencia de mujeres con diagnóstico cáncer de mama, se problematiza dicha vivencia en vinculación directa con la biomedicina moderna que circunscribe la enfermedad a un cuerpo objetivo. El tema de la corporeidad se torna en la discusión central. La propuesta merleaupontyana del cuerpo vivido o fenomenal como sujeto experiencial permite una apertura hacia derroteros a explorar, permitiendo repensar los procesos de salud/enfermedad y tomando distancia de acepciones de índole restitutivas.

PALABRAS CLAVE experiencia. enfermedad. habitud. corporalidad. biomedicina

The article reflects on the experience of the illness from the phenomenology of Merleau-Ponty. Experience of the order of the disruptive, which introduces the dimension of the unusual, the illness is assumed as a necessary reconfiguration of the body schema. In the framework of a research about the experience of women diagnosed with breast cancer, this experience is problematized in direct linkage with modern biomedicine that circumscribes the illness to an object body. The theme of corporeality becomes the central argument. The merleaupontyan proposal of the lived or phenomenal body as experiential subject allows an opening towards paths to be explored, allowing to rethink the processes of health/illness and taking distance from meanings of restitutive nature.

KEYWORDS experience. illness. habitude. corporality. biomedicine 


\section{Introducción}

El artículo reflexiona en torno a la experiencia de la enfermedad desde la fenomenología de Merleau-Ponty. Experiencia del orden de lo disruptivo, que introduce la dimensión de la inhabitualidad. En el marco de una investigación acerca de la experiencia de mujeres con diagnóstico cáncer de mama, se problematiza dicha vivencia en vinculación directa con la biomedicina moderna que circunscribe la enfermedad a un cuerpo objetivo. El tema de la corporeidad se torna en la discusión central. La propuesta merleaupontyana del cuerpo vivido o fenomenal como sujeto experiencial, permite una apertura hacia derroteros a explorar.

En una primera parte del artículo, se recorren algunos de los principales conceptos que guían la problematización merleaupontyana. Esto se refuerza en un segundo apartado, donde la pregunta se dirige a cuestionar por qué es importante considerar la experiencia de la enfermedad en una filosofía del cuerpo vivido y en particular, cuáles son sus aportes para una reflexión crítica capaz de interpelar la concepción biomédica hegemónica en torno a la demarcación normal/patológico. La experiencia encarnada de la enfermedad, caracterizada justamente como disrupción e inhabitualidad permite mantener abierto el pensamiento interrogativo, propiciando así la función crítica de la filosofía.

\section{La experiencia corpórea-perceptiva: un abordaje desde la filosofía merleaupontyana}

La noción de experiencia en la fenomenología merleaupontyana remite casi inmediatamente al cuerpo como fundamento de nuestra participación en el mundo. Se trata de un cuerpo que, siguiendo la distinción que realizara Husserl, se interesa por el cuerpo vivido que somos, Leib, en contraposición al cuerpo que puede ser circunscrito al pensamiento objetivo en tanto Körper. Nos detendremos en esta distinción unos parágrafos más adelante, aunque es propio destacar que en Merleau-Ponty, será a las claras, el cuerpo vivido fenomenológico el que ocupará el centro de interés.

Nuestro cuerpo resulta horizonte de nuestra experiencia, se trata de un cuerpo en situación. Mi cuerpo es el quicio del mundo, dirá Merleau-Ponty, para referir al cuerpo vivido como vehículo de ser-del-mundo, a partir del cual conectamos con un mundo definido, nos confundimos con ciertos proyectos y nos conectamos con ellos (MERLEAU-PONTY, 1985: 101). Tengo consciencia del mundo por medio de mi cuerpo, y esto también supone que actúa como 
fondo sobre el cual emerge toda relación, cuna de la intersubjetividad y de la figuración del sentido.

La noción de cuerpo vivido se presenta más allá y en las antípodas del dualismo cartesiano que diferencia cuerpo y alma, definiendo el cuerpo como una suma de partes sin interior y el alma como un ser totalmente presente a sí mismo sin distancia, dirá Merleau-Ponty. Dualismo que ha subsumido el cuerpo como lugar secundario, objeto de intervención, mera extensión del alma, "inventariada entre los obstáculos del camino hacia el bien, como una prisión o tumba (sêma) para el alma caída, (...) un mal necesario, un problema ontológico, una fuente de error o de una maldad, una falla de nuestra naturaleza" (GARCÍA, 2012: 10).

El gesto filosófico cartesiano debe circunscribirse a determinado contexto histórico, cultural y político en particular, inaugurando lo que pasaría a ser el comienzo de la ciencia moderna, basada en la observación objetiva y cuantitativa de la naturaleza física. En este contexto, el cuerpo pasa a constituirse en materia, subsumido al registro del "tener", intentando borrar todo vestigio de subjetividad como todo aquello que se aparte del paradigma físico. A partir del siglo XIV comienzan a realizarse las primeras disecciones oficiales, siendo Leonardo da Vinci (1452-1519) y Vesalio (1514-1564) algunos exponentes de la época (GARCÍA, 2012: 38). El cuerpo, materia, aspecto maleable y objetivable fue ubicado del lado de los objetos, sustrayendo la dimensión inherentemente subjetiva de la corporalidad, una alienación de la subjetividad respecto del cuerpo en términos de Ricoeur (1996).

Pensar entonces qué es el cuerpo más allá de Descartes, resultó para Merleau-Ponty un camino no sin dificultades, y recurre para ello a la fenomenología de Husserl, como filosofía de la "conciencia trascendental". No nos detendremos en la obra de Husserl, ni en sus diferentes etapas y diálogos con Descartes. Simplemente, indicar que Merleau-Ponty retoma fundamentalmente de la etapa "genética" de la fenomenología de Husserl, de las Meditaciones cartesianas, la consideración de uno de los puntos de partida principales de su obra, a saber, que "ya no es posible separar una conciencia pura de la facticidad del mundo de la historia (...) la conciencia husserliana es una conciencia encarnada y de ese modo, contaminada por el mundo" (GARCÍA, 2012: 54). De aquí se comprende que para Merleau-Ponty, por estar en el mundo estemos condenados al sentido y no podamos decir nada que no tome un nombre en la historia (1985: 19).

El cuerpo tiene en la experiencia un carácter subjetivo: soy mi cuerpo, lo cual nos revela un modo de existencia más ambiguo cuya unidad es siempre implícita y confusa (MERLEAU-PONTY, 1985: 215). Advertimos de este modo 


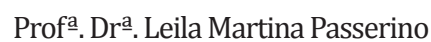
[Universidad de Buenos Aires, Argentina]

que el cuerpo se torna sujeto experiencial. Nuestro cuerpo es nuestra forma de ser-en-el-mundo, de pertenecer al mundo, síntesis inacabada. Desde el mundo vivido de los fenómenos perceptuales, nuestros cuerpos dejan de ser objetos para constituirse en parte integral del sujeto que percibe.

El cuerpo forma parte de este ser que presupone una visión pre-objetiva del cuerpo, desde la cual, el último no está en el mundo como una cosa, sino como intencionalidad. Así es como reproduce la paradoja de la existencia: el cuerpo nos sitúa en el escenario del mundo y es una de las manifestaciones del mundo; se comporta como un sujeto porque es siempre perceptor de lo percibido, pero, a la vez, es lo percibido que percibe'. (LÓPEZ SÁENZ, 2010: 95)

Arribamos de esta manera a otro de los aspectos claves de la fenomenología merleaupontyana que también hunde sus raíces en la filosofía husserliana. La experiencia, dirá este autor, consiste básicamente en percibir, la percepción es la "experiencia primaria" propia de una conciencia "encarnada", lo cual otorga al cuerpo un lugar trascendental y no accesorio de la experiencia ni apartado de ella (GARCÍA, 2012: 55). En términos de Merleau-Ponty, esta consigna que daba Husserl a la fenomenología de volver "a las cosas mismas" implica que no podemos pensarnos como parte del mundo, como simple objeto de la ciencia. Todo lo que sabemos del mundo — incluso por la ciencia misma - es producto de una visión más o de una experiencia del mundo sin la cual nada significarían los mismos símbolos de la ciencia (MERLEAU-PONTY, 1985: 8).

El estudio de la corporalidad y la percepción nacen de una crítica epistemológica hacia lo que comprendemos como percepción, punto de partida primero para un abordaje de la corporalidad como apertura al mundo: "La percepción tiene su sede en el cuerpo, la percepción es por necesidad una función propia

1 En sus últimas obras, Merleau-Ponty empleará el término Chair, más englobante que el de "cuerpo", como núcleo de su nueva ontología. La carne procura borrar los rastros de positividad que pudiera sugerir todavía el concepto de cuerpo. Como advierte Ariela Battán Horenstein, en Fenomenología de la percepción (1945) la comprensión del cuerpo fenomenal todavía está atada a la definición del cuerpo objetivo y a la conciencia. Éste sirve como piedra de toque y punto de partida; lejos de hacer del cuerpo una imposición conceptual a priori o una herramienta teórica, lo rescata del ámbito de las cosas mediante la reducción de las certezas con que el pensamiento objetivo lo había revestido para colocarlo en el centro de las experiencias motrices o expresivas del sujeto. La inauguración de una ontología de la carne y la rehabilitación de lo sensible hicieron posible que el cuerpo adquiriera luego un lugar fundamental en esa nueva configuración quiasmática, donde se reconcilian y reúnen la idea y lo sensible, lo visible y lo invisible, el sintiente y lo sentido $(2013: 16,17)$. 
de un cuerpo percipiente". (GARCÍA, 2012: 85). La percepción no es una relación diádica entre un sujeto y un objeto, sino que rebasa tales dicotomías. Merleau-Ponty se encargará en extensas páginas de realizar una crítica pormenorizada contra los abordajes del empirismo y el intelectualismo en torno a la percepción.

Respecto al empirismo podemos decir que el autor se vale de la Teoría de la Gestalt para, por un lado, demostrar que no hay dato sensible que dependa inmediatamente de los órganos de los sentidos: el menor dato sensible no se ofrece más que integrado a una configuración y ya "puesto en forma" (MERLEAU-PONTY, 1985: 177). No hay sensación por la impresión pura. Cada punto no puede percibirse como una figura sobre un fondo. Desde este punto de vista,

El “algo" perceptivo está siempre en el contexto de algo más, siempre forma parte de un "campo". (...) La estructura de la percepción efectiva es la única que puede enseñarnos lo que sea percibir. La impresión pura no sólo es, pues imposible de hallar, sino también imperceptible y por ende, impensable como momento de la percepción. (MERLEAU-PONTY, 1985: 26)

Lo que impide por tanto esa identificación es la adherencia de lo percibido a su contexto, su viscosidad dirá el autor, como la presencia en el mismo de algo positivamente indeterminado como domino preobjetivo (MERLEAU-PONTY, 1985: 34).

Respecto al intelectualismo, Merleau-Ponty discute con Descartes y Kant el haber desvinculado el sujeto o la conciencia del acto de conocer, esto es, asimilar la percepción como perteneciente al orden del juicio de los actos o de la predicación.

La realidad está por describir no por construir o constituir. Esto quiere decir que no puedo asimilar la percepción a las síntesis que pertenecen al orden del juico, de los actos o de la predicación. En cada momento mi campo perceptivo está lleno de reflejos, de fisuras, de impresiones táctiles fugaces que no estoy en condiciones de vincular precisamente con el contexto percibido y que no obstante, sitúo desde el principio en el mundo (...) El mundo no es un objeto cuya ley de constitución yo ten- 
dría en mi poder, es el medio natural y el campo de todos mis pensamientos y de todas mis percepciones explícitas (...) el hombre está en el mundo, es en el mundo que se conoce". (MERLEAU-PONTY, 1985: 10, 11)

Así, el mundo ya no se propone como objeto frente a mí, ni tampoco yo me constituyo en pura conciencia, sino que por ser esencialmente cuerpo, estoy mezclado en el mundo:

Organizo con mi cuerpo una comprensión del mundo y la relación con mi cuerpo no es la de un Yo puro que tendría sucesivamente dos objetos, mi cuerpo y la cosa, sino que yo habito mi cuerpo y por él habito las cosas. La cosa se me aparece [...] como enclavada en su funcionamiento.

(MERLEAU-PONTY, 1995: 106 en GARCÍA, 2012: 87)

No existe un ente previo, materia, desprovista de sentido sobre la cual una conciencia en términos exteriores la piensa, sino más bien, la percepción se desliza y se funda como horizonte de sentido.

La percepción, su encarnación, no ofrece ningún carácter positivo del que deba darse cuenta [un origen de la percepción], y su ecceidad no es más que la ignorancia en que se encuentra de sí mismo (MERLEAU-PONTY, 1985: 59), de aquí el carácter prereflexivo, incorporado, inconsciente. La percepción se da como totalidad, dirá el autor, y como unidad antes que hayamos captado su ley inteligible: "En la percepción efectiva, y tomada en estado naciente, anteriormente a toda palabra, el signo sensible y su significación ni siquiera idealmente son separables" (MERLEAU-PONTY, 1985: 60). Hay siempre una distancia entre yo que analizo la percepción y el yo perceptivo. Pero en el acto concreto de la reflexión salvo esta distancia, demuestro con ello que soy capaz de saber lo que yo percibía, domino prácticamente la discontinuidad de los dos yo, y el sentido que, finalmente, el cogito tendría, no sería el de revelar un constituyente universal ni de reducir la percepción a la intelección, sino el constatar este hecho de la reflexión que domina y mantiene a la vez la opacidad de la percepción (MERLEAU-PONTY, 1985: 64, 65). De este modo, dirá Merleau-Ponty, el cartesianismo, como el kantismo, habría visto el problema de la percepción consistente en ser un conocimiento originario. Pero esta percepción empírica o segunda oculta este fenómeno fundamental porque está colmada de adquisiciones antiguas. Lo cual hace que las operaciones de la conciencia no sean nunca 
absolutamente transparentes a sí mismas, sino que sucedan en una conciencia ambigua, caracterizada por su opacidad, expresado en Husserl a partir de la sedimentación pasada de las habitualidades. De este modo, "no solamente el sentido de mi vida escapa de sí mismo a la vez que se construye sino que en última instancia los horizontes temporales de mi vida personal se difumina y se hunden en la oscuridad, la indeterminaciones y el sinsentido" (GARCÍA, 2012: 168).

La percepción, desde la filosofía merleaupontyana, como hemos aludido, no depende de un proceso intelectual ni meramente fisiológico. La preocupación del filósofo no es buscar las condiciones de la percepción — cómo si lo harían estas corrientes - sino dar cuenta de las operaciones que la actualizan y que en caso de Merleau-Ponty, estará centrada en las disposiciones motrices sedimentadas por el hábito, lo cual caracteriza el espesor viviente de la percepción.

El cuerpo integra e interpreta el mundo, lo objetiva de acuerdo a los comportamientos posibles y a su contexto práctico, esto es, en tanto sentido práctico en relación a una comunidad cultural. Los movimientos del propio cuerpo están naturalmente investidos de una cierta significación perceptiva, dirá el filósofo: "El análisis del hábito motor como extensión de la existencia se prolonga pues, en un análisis del hábito perceptivo como adquisición de un mundo. Recíprocamente, todo hábito perceptivo es aún un hábito motor y aquí también la captación de una significación se hace por el cuerpo" (MERLEAU-PONTY, 1985: 169). De este modo, no percibo el signo en mi cuerpo, sino hago signo a través del mundo (MERLEAU-PONTY, 1985: 129).

El sujeto percipiente actúa como cuerpo portador de determinadas posibilidades y disposiciones de movimiento, un "esquema corporal" - concepto que retomaremos en el próximo apartados. El sujeto y el objeto de la percepción definidos como "esquema corporal" y "fórmula motriz" sugieren un nuevo tipo de relación entre ellos, ya no como términos independientes sino mutuamente motivados, partícipes de una misma estructura o "sistema" (GARCÍA, 2012: 92). Por mi cuerpo, organizo una comprensión del mundo, habito mi cuerpo y por él habito las cosas. La percepción entonces puede pensarse como recorrido o proyecto pragmático atado a mis habitualidades o disposiciones motrices sedimentadas. El mundo, la naturaleza, exceden en este punto la conciencia perceptiva, como ya señalaba la Fenomenología, pero este exceso se da sólo en la misma percepción, en tanto lo percibido prolonga sus horizontes hasta lo no percibido y aún lo imperceptible (GARCÍA, 2012: 17). Así la percepción actúa como Gestalt integrando diversos elementos, no pudiendo determinarlos dada su indeterminación última. En esta dirección, dirá Merleau-Ponty, no hay nada 
más difícil que saber exactamente lo que vemos, en la medida que nunca recuperamos efectivamente todos los pensamientos originarios que contribuyen en mi percepción o mi convicción presente (MERLEAU-PONTY, 1985: 79, 82).

Las disposiciones motrices como modalidades particulares de ser-en-el-mundo, operan como hábitos, una practognosia como lo define Merleau-Ponty, para dar cuenta de los saberes instituidos progresivamente en términos de habitualidades, en los modos de adherirnos al mundo y resolver diferentes dilemas prácticos:

La experiencia motriz de nuestro cuerpo no es un caso particular de conocimiento; nos proporciona una manera de acceder al mundo y al objeto (...) Mi cuerpo tiene su mundo o comprende su mundo sin tener que pasar por unas "representaciones", sin subordinarse a una "función simbólica" u "objetivante".

(MERLEAU-PONTY, 1985: 160)

La adquisición de habilidades perceptivas resulta un saber del cuerpo, un sentido práctico, es el cuerpo el que atrapa y comprende el movimiento, tales como aprender a caminar o a bailar. La comprensión existencial es derivada de un stock o reservorio cultural. Esta maestría o saber corporal permite adquirir hábitos motores, es decir, que no son meramente pasivos, sino capaces de dilatar el mundo y poner a prueba la existencia (LÓPEZ SÁENZ, 2010: 93), lo cual implica una destreza corporal e indisolublemente una aprehensión de sentido. Por ello el autor explica que: "La adquisición de la habilidad es la captación de una significación, pero la captación motriz de una significación motriz” (MERLEAU-PONTY, 1985: 160).

La noción de cuerpo vivido (Leib) permite así problematizar la noción de que cuerpo que ha predominado en el terreno de la fisiología como en el de la psicología mecanicista. El Leib es distinguido por Husserl del cuerpo que las ciencias físicas, biológicas o anátomo-fisiológicas pueden describir como un objeto del mundo, por cuanto ha pasado a tener un sentido trascendental y constituyente de mundo (GARCÍA, 2012: 64). Las ciencias obvian esta experiencia vivida del cuerpo en nombre de un ideal de conocimiento objetivo y se ocupan sólo del Körper. Pero este abordaje resulta problemático en la medida que el énfasis en los aspectos orgánicos de los procesos de dolencia y cura conducen a una omisión de la dimensión de sentido que reviste tales procesos, limitando las explicaciones de ciertos fenómenos del cuerpo: el cuerpo/objeto de las ciencias médicas sustituye el cuerpo vivido, fuente y condición para nuestra relación con un mundo de objetos (RABELO; ALVES; SOUZA, 1999: 13). 
Tanto Leib como Körper resultan estructuras integradas e inherentes a toda disposición en-el-mundo. No puede decirse que el cuerpo objetivo y el fenoménico sean cuerpos separados, pues se relacionan como dos estructuras integradas: si aquél es el depositario de procesos fisiológicos automáticos y el fondo de todas nuestras actividades, éste es la expresión y realización de intenciones, proyectos y deseo. Todo hecho objetivo sobre el cuerpo objetivo produce consecuencias que sólo son inteligibles para el cuerpo fenoménico; este no designa, frente a aquél la idealidad del cuerpo; no es un constructo, sino la condición de "sujeto generalizado, la invasión de las situaciones naturales e históricas" (LÓPEZ SÁENZ, 2010: 96).

Las situaciones patológicas, son consideradas así como variaciones y modalidades del ser total del sujeto y no como afección "localizada", externa a quien la transita. En este sentido, se trata de aprender "de nuevo a sentir nuestro cuerpo, hemos reencontrado bajo el saber objetivo y distante del cuerpo este otro saber que del mismo tenemos, porque está siempre con nosotros y porque somos cuerpo" (MERLEAU-PONTY, 1985: 222).

De modo que, no disponemos de ningún otro medio de conocer el cuerpo humano más que en la vivencia - en la enfermedad, como el drama que me atraviesa y me confunde con él - experiencia que la ciencia procura dejar de lado o ubicar a lo sumo en un lugar secundario.

\footnotetext{
Así pues, soy mi cuerpo, por lo menos en toda la medida en que tengo un capital de experiencia y recíprocamente mi cuerpo es como un sujeto natural, como un bosquejo provisional de mi ser total. Así la experiencia del propio cuerpo se opone al movimiento reflexivo que separa al objeto del sujeto y al sujeto del objeto, y que solamente nos da el pensamiento del cuerpo o el cuerpo en realidad. (MERLEAU-PONTY 1985: 216)
}

El cuerpo no es objeto de mi percepción sino siempre a la vez sujeto, este entrelazamiento único del objeto y el sujeto de la percepción en el cuerpo propio será enfatizado por Merleau-Ponty para afirmar que la subjetividad autoconsciente en el sentido cartesiano - el pensamiento que "esbozo de reflexión" - es anticipada por esta más originaria autoconciencia corporal: hay un "yo tácito" del cuerpo, dirá Merleau-Ponty, en el que funda sus operaciones el yo consciente. (GARCÍA, 2012: 64). El autor da el ejemplo del dolor. En la experiencia del dolor, mi pie no aparece como causa objetiva del dolor (como el 
clavo que lo desgarra), como representación interna. Decir "me duele el pie" es circunscribirlo a un "espacio doloroso" como "sujeto" de la sensación, y no como una relación que solamente vincularía al pie por una determinación causal y en el sistema de experiencia (MERLEAU-PONTY, 1985: 111).

Las ciencias no se desarrollan sin el cuerpo vivido, aunque bajo las pretensiones de objetividad y pensamiento positivo, expresadas en la estadística, se tienda a borrarlo. El mismo Merleau-Ponty afirma que los fenómenos nunca son ignorados por la conciencia científica que toma prestados a la estructura de la experiencia vivida todos sus modelos; lo que simplemente ocurre es que la consciencia científica no los "tematiza", no explicita los horizontes de consciencia perceptiva de que está rodeada y cuyas relaciones concretas intenta expresar objetivamente (MERLEAU-PONTY, 1985: 79). De este modo, opera un olvido, que no necesariamente significará ausencia, solo los ignora, dirá el autor, en favor de las cosas porque son ellos la cuna de las mismas.

Esta separación de la ciencia respecto a la experiencia que la fundó, era ya indicada por Husserl y también por Georges Canguilhem, quien afirmaba que "El fisiólogo tiende a olvidar que una medicina clínica y terapéutica (...) ha precedido a la fisiología" y "el médico tiende a olvidar que son los enfermos quienes llaman al médico" (CANGUILHEM, 1966: 159 en GARCÍA, 2009: 528, 529). Esteban García retoma esta cita y advierte las consecuencias terapéuticas de tal olvido, en la que el privilegio en el diagnóstico de la "observación anatómica e histológica, el test fisiológico o el examen bacteriológico" prevalece por sobre la experiencia de un cuerpo íntegro en el cual se entrelazan indisociablemente más dimensiones que las cuantificables.

Se trata aquí de una serie histórica y epistemológica de fundamentación del sentido de los conceptos científicos en la que no hay que perder ningún término: la ciencia fisiológica se funda en la fisiopatología, la cual se funda en una técnica terapéutica - en nuestra cultura, la clínica médica - la cual responde a su vez a la experiencia humana del dolor y la enfermedad tal como son vividos. (GARCÍA, 2009: 529)

El valor de los desarrollos merleaupontyanos acerca del cuerpo vivido es reconocido explícitamente por Canguilhem quien afirma que "La definición de la salud que incluye la referencia de la vida orgánica al placer y al dolor 
experimentados como tales introduce subrepticiamente el concepto de cuerpo subjetivo en la definición de un estado que el discurso médico cree poder describir en tercera persona" (CANGUILHEM, 2004: 63 en GARCÍA, 2009: 529).

En la enfermedad, advertimos la ambigüedad de la existencia corporal como es vivida, lo cual implica no reducirla puramente ni a las condiciones fisiológicas o psicologistas. Merleau-Ponty en Fenomenología de la percepción, retoma la experiencia del miembro fantasma y la anosognosia, para elucidar la experiencia del cuerpo tal como es vivida, aunque es posible extender esta indagación para el estudio de estas modalidades y variaciones del ser total de sujeto. ¿Qué implica la experiencia de la enfermedad? Revisaremos estos aspectos en el próximo apartado.

\section{Experiencia y enfermedad: la irrupción de la inhabitualidad}

La experiencia de la enfermedad ocupa un lugar importante en el desarrollo merleaupontyano. Pero no lo hace por el fenómeno de estar enfermo en sí o por la enfermedad como conmoción de la existencia del ser individual como sí le interesa Goldstein (LÓPEZ SÁENZ, 2010: 102), sino más bien porque le permite deslizar una crítica epistemológica y superar los abordajes intelectualistas y empiristas de la percepción en pos de una comprensión holística del cuerpo en tanto ontología de la carne.

Determinados eventos, como el caso prototípico de la enfermedad o el dolor, provocan que "aparezca el cuerpo". Desde este punto de vista, la experiencia de la enfermedad se esgrime como disrupción en el modo de ser-en-el-mundo y por esto requiere una reorganización de nuestras habitualidades: "Mi cuerpo es este núcleo significativo que se comporta como una función general y que no obstante, existe y es accesible a la enfermedad. En él aprendemos a conocer este nudo de la esencia y la existencia que volveremos a encontrar, en general, dentro de la percepción (...)" (MERLEAU-PONTY, 1985: 164). La vida cotidiana ignora el cuerpo en la medida en que se proyecta sin problemas y este pasa desapercibido, como así también su ambivalencia y finitud. La enfermedad reduce la esfera de la acción corporal, como las posibilidades prácticas, generando esta conciencia del ser corporal que nos pone frente a frente y que provoca cierta extrañeza con nuestras habitualidades: "La relación entre el cuerpo vivido y el medio cambia con la enfermedad: el mundo que nos rodea se transforma y se siente de otro modo. Esto es lo que podemos deducir de la feno- 
menología del cuerpo vivido que desarrolla nuestro filósofo" (LÓPEZ SÁENZ, 2010: 102). Nuevamente, debemos interpretar estos movimientos desde una teoría de la Gestalt, experimentamos la enfermedad porque hay un horizonte previo de habitualidad que amenaza nuestro anclaje en el mundo.

Para una fenomenología centrada en la corporalidad como horizonte de toda experiencia y locus de nuestras habilidades sensorio-motoras, el cuerpo sano es esa transparencia por la que nos comprometemos con el mundo. Nos resulta tan familiar que no lo convertimos en tema (LÓPEZ SÁENZ, 2010: 100). De aquí la famosa frase de Leriche, retomada por Canguilhem, que dice " $\mathrm{La} \mathrm{sa}$ lud es la vida en silencio de los órganos" (CANGUILHEM, 2005: 63). En la enfermedad, se produce un quiebre, dado que rompemos con esa familiaridad, el cuerpo puede volverse una presencia extraña - como alienación o extrañamiento - que molesta a los hombres en el normal ejercicio de su vida y en sus ocupaciones y sobre todo aquello que los hace sufrir: "El estado de salud es la inconciencia del sujeto con respecto a su cuerpo. A la inversa, la conciencia del cuerpo se produce en el sentimiento de los límites, de las amenazas, de los obstáculos para la salud" (CANGUILHEM, 2005: 63).

En el encuentro clínica o consulta médica, ha de darse una situación paradójica, dado que "el paciente conceptualiza, además, su cuerpo como ser-paraotro u objeto de investigación científica, para experimentar la ambigüedad de su cuerpo, es decir, esa extraña dualidad de sentirse, a la vez, sujeto para sí y objeto para otro" (LÓPEZ SÁENZ, 2010: 101). Esta objetividad o instrumentalización que hacemos del cuerpo - por ejemplo, cuando sufro un esguince en el tobillo, se me aparece explícitamente como un instrumento para caminar que ahora me lo impide - otorga una cierta "verdad" a la ontología dualista cartesiana que piensa el cuerpo como descripción mecánica u objetiva.

E. García argumenta que esta "verdad" presente en la descripción científico-objetiva del cuerpo, en efecto habilita ciertas posibilidades de la experiencia o dimensiones de la corporalidad, un pliegue. Aparentemente Descartes tendrá entonces a fin de cuentas, alguna razón para afirmar que "yo no soy el cuerpo". En La estructura del comportamiento, Merleau-Ponty enuncia que:

La conciencia descubre $[\ldots]$ en particular durante la enfermedad, una resistencia del cuerpo propio. Puesto que una herida en los ojos basta para suprimir la visión, es que vemos entonces a través del cuerpo. Puesto que una enfermedad basta para modificar el mundo fenoméni- 



[Universidad de Buenos Aires, Argentina]

co, es entonces que el cuerpo hace pantalla entre nosotros y las cosas. (MERLEAU-PONTY, 1976: 264 en GARCÍA, 2012: 122)

La "verdad" del dualismo estriba en esos momentos en que el cuerpo parece interponerse como una cosa más entre mi conciencia perceptiva y las cosas.

Ahora bien, como expresa García, este cuerpo que "no soy yo" aunque no puedo despegar de mí, este cuerpo "objetivado" o "alienado" — otro o extraño a mí - por la mirada de los otros, por la mirada de la medicina, no constituye una expresión contingente de una subjetividad que podría existir separada de su "expresión"/“realización" (GARCÍA, 2012: 123). Así, este dualismo resulta en efecto una descripción de la experiencia corporal, que aunque efectista, encubre al cuerpo vivido como matriz senso-perceptiva, razón que lleva a Merleau-Ponty a resistir esta objetivación - evidenciado por el autor a partir del análisis del dolor, que como ya hemos mencionado, resulta ejemplo concreto de la imposibilidad de reducir el cuerpo a una descripción en tercera persona. Por ello, si bien como advierte Merleau-Ponty en la experiencia de la enfermedad, el cuerpo parece escindirse de mi ser-en-el-mundo y asumir una autonomía capaz de extrañeza y ajenidad, no es menos cierto que la experiencia de la enfermedad nos revela la imposibilidad de separarnos de esos procesos, que muchas veces no controlamos o nos superan. Nunca dejo de ser mi cuerpo y por ello la enfermedad no es más que conciencia corporal encarnada, un cuerpo desgarrado en sus contradicciones, en guerra consigo mismo y llamando a otros oídos y otras miradas para reconocerse, reintegrarse a sí mismo y al mundo, y volver a ser así ese "centinela mudo" e invisible que permanece detrás de todos mis actos y mis palabras (GARCÍA, 2009: 530).

En síntesis, el dualismo describe ciertas posibilidades de la experiencia, pero también obtura otro tipo de indagación y saberes. Este aspecto puede y ha resultado problemático, dado que perpetuar las formas de ver el cuerpo, como lo ha hecho hegemónicamente la medicina, en tanto cuerpo-enfermo o considerado como objeto perdido no ofrece posibilidades de crecimiento y afirmación (WILDE, 2003), condiciones de habitualidad podríamos decir en términos de Merleau-Ponty².

2 Desde el estudio marco en el cual se desarrolla esta reflexión, este tipo de argumentos es el que sostiene cierta solución a la problemática del cáncer de mama con la recomendación de una cirugía reconstructiva (como restitución de un objeto perdido). En esta línea se sostiene toda una psicopatologización que reduce el cuerpo en tanto sustento físico de un Ego trascendental y que desconoce otros procesos que no resultan de la "teta" en sí, sino del horizonte de sentido y la historia del cuerpo vivido en contextos culturales particulares. Se enmascaran así otros procesos y ansiedades que pueden desprenderse, y que no siempre habilitan mejores condiciones de habitabilidad, solapándose con mecanismos sexo-generizados de control social. 
Recuperemos las experiencias de enfermedad que analiza Merleau-Ponty a fin de avizorar los límites de los abordajes fisiologistas como psicologistas, que el autor desliza en línea a su crítica epistemológica, a la cuestión de la percepción y que resultarán fructíferos para comprender las nociones de cuerpo actual y cuerpo habitual, como sus derroteros para la interpretación de los procesos de salud/enfermedad. En Fenomenología de la Percepción, el autor presenta, entre otros, el caso del miembro fantasma y la anosognosia.

Una explicación fisiológica interpreta a la anosognosia y al miembro fantasma como la simple supresión o la persistencia de las estimulaciones interoceptivas - representaciones ocasionadas por estímulos o por la falta de ellos. En esta hipótesis, la anosognosia es la ausencia de un fragmento de la representación del cuerpo que debería darse, ya que el miembro correspondiente está ahí; el miembro fantasma es la presencia de una parte de la representación del cuerpo que no debería darse, ya que el miembro correspondiente no está ahí. Desde una explicación psicológica de los fenómenos el miembro fantasma es considerado un recuerdo, un juicio positivo o una percepción y la anosognosia un olvido, un juicio negativo o una impercepción. En el primer caso, el miembro fantasma es la presencia efectiva de una representación. En el segundo, el miembro fantasma es la representación de una presencia efectiva; la anosognosia, la representación de una ausencia efectiva. En los dos casos no salimos de las categorías del mundo objeto en donde no hay un medio entre presencia y la ausencia. (MERLEAU-PONTY, 1985: 99).

Como queda expuesto, los intentos de explicación tanto de la anosognosia como del miembro fantasma desde las explicaciones fisiológicas y psicológicas, resultan limitantes dado que no logran salir de las "categorías del mundo objetivo": la enfermedad entendida en estos términos se limita a ser sólo una modificación cuantitativa, tengo dos brazos, tengo sólo un brazo, tengo ciertas posibilidades de acción, tengo menos, antes tenía una pierna, ahora una construcción fantasmagórica (BATTÁN HORENSTEIN, 2008: 5).

Merleau-Ponty induce a concebir la enfermedad desde otros derroteros. A partir de una concepción del cuerpo-vivido, la enfermedad se comprende como perspectiva del ser-del-mundo, donde lo patológico no resulta de la ausencia o presencia de un miembro en sí, sino más bien de aquello que puede ser indicador de una deficiencia no asumida como tal (BATTÁN HORENSTEIN, 2008: 5). La enfermedad se circunscribe de esta manera, como ese momento de transición en el cual se ponen en tensión la manera habitual de ser-en-el-mundo. Por tanto, no es concebida tanto como un hecho observable y localizable (empirismo) que 
afecta al ser pasivamente, sino más bien como un estilo de percibir la existencia, una manera de ser-en-el-mundo que supone una reorganización de nuestra vida. Así, desde el mismo ejemplo que da Merleau-Ponty, el brazo fantasma no resulta una representación del brazo, sino la presencia ambivalente de un brazo.

A título explicativo, el rechazo de la mutilación, en el caso del miembro fantasma o el rechazo de la deficiencia, en la anosognosia, no son decisiones deliberadas, no se dan en el plano de la consciencia tética que toma explícitamente disposición después de haber considerado diferentes posibilidades (MERLEAU-PONTY, 1985: 100). Poseer así un brazo o miembro fantasma, expresará el filósofo francés, es permanecer abierto a todas las acciones que sólo el brazo es capaz, es guardar el campo práctico que poseía antes de la mutilación y no, una representación mental. La experiencia del cuerpo, se traduce así en un repertorio de posibilidades de movimiento y de aquí esa presencia ambivalente, anterior a toda decisión deliberada, que lleva a la persona a ajustarse gradualmente, a experienciar corporalmente el mundo de otra forma, adquirir nuevos hábitos de movimiento, en virtud de su vivencia actual de la unidad del esquema corporal que le sigue proporcionando una experiencia corporal unitaria (LÓPEZ SÁENZ, 2010: 99). Así, esta experiencia de un brazo amputado como presente o de un brazo enfermo como ausente, no son del orden del "yo pienso que...", no se formulan por sí mismos. Merleau-Ponty señala que aquello que rechaza la mutilación y la deficiencia es un Yo empeñado en cierto mundo físico e interhumano, un Yo que continúa tendiéndose hacia su mundo pese a deficiencias o amputaciones, y que en esta medida no las reconoce de iure (MERLEAU-PONTY, 1985: 100). Por eso, si la persona amputada trata a su brazo como un miembro real, es porque poseer un brazo fantasma es permanecer abierto a todas las acciones de las que sólo el brazo es capaz, es guardar el campo práctico que uno poseía antes de la mutilación y confundirse y comprometerse con ciertos proyectos.

Los casos presentados por Merleau-Ponty, ilustran la ambivalencia que operara como hiato entre cuerpo actual y cuerpo habitual. El cuerpo siempre se presenta como síntesis acabada, esquema corporal en el que cuerpo y mundo se configuran mutuamente produciendo una manera de ser-cuerpo en términos de repertorio de posibilidades percepto-motrices. El cuerpo habitual es reservorio de gestos aprehendidos, incorporados, y por ello se dice que permanece anónimo, impersonal dado que en la expresión subyace una familiaridad bajo disposiciones estables - como saber implícito contenido en el cuerpo antes de todo pensamiento tético, lo cual borra la especificidad de la instancia de aprendizaje manifestada en la expresión: 


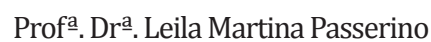
[Universidad de Buenos Aires, Argentina]

\begin{abstract}
El cuerpo habitual está atravesado por una espacialidad y una temporalidad, en una restructuración permanente que se sólo se fija en la muerte en o en la enfermedad. Esta característica de reorganización permanente es lo que posibilita el refuerzo y formación de los hábitos, que actúan según el sentido de la situación y no como montajes mecánicos.
\end{abstract}

(COLECLOUGH, 2010: 42)

El cuerpo actual es aquel captado por la experiencia singular instantánea, el cuerpo con sus características actualmente observables y que muevo a voluntad. En la experiencia de la enfermedad es el cuerpo actual el que prima, desdibujando la familiaridad que teníamos e interpelándonos, de modo que aquella existencia cristalizada en ciertas disposiciones motrices desaparecen y este tiende al tiempo "presente" — un antiguo presente que no se decide a devenir pasado, dice Merleau-Ponty - por oposición a un "pasado presente" del cuerpo habitual - que no necesita ser traído explícitamente a la conciencia por medio de un recuerdo, sino que está constantemente operando en el presente de modo latente o en una "seminconsciencia", determinado el campo de nuestras posibilidades de acción y percepción (GARCÍA, 2012: 112).

Los casos del miembro fantasma y la anosognosia presentados en Merleau-Ponty ilustran como decíamos esa ambigüedad de toda sensación, presente en toda enfermedad, que establece un hiato entre el cuerpo habitual y el cuerpo actual. En estas situaciones nos vemos interpelados y es el momento en que podríamos reconocer cierta "verdad" del dualismo de la que hablaba el filósofo. El esquema corporal integra ambas dimensiones, actúa, y mientras se "recompone" en el sujeto de la enfermedad, "sigue garantizándole la capacidad de realizar sus proyectos en el mundo, ya que actúa como un stock de sedimentaciones que organiza y coordina todas las formas actuales o posibles de actividad corpórea" (LÓPEZ SÁENZ, 2010: 99). Este aspecto da cuenta del dinamismo en la "renovación" del esquema corpóreo, lo que hace que el cuerpo vivido y el mundo percibido tengan la plasticidad suficiente para "reestructurase" e integrar las disposiciones en términos de nuevos hábitos, aunque nunca pudiendo dar cuenta de su origen primero. El esquema corporal, por tanto, se pone de manifiesto en el movimiento, dotando al cuerpo de un saber implícito que se proyecta de manera indeterminada hacia un ámbito de recorridos posibles.

Los casos patológicos expuestos, junto con la crítica epistemológica que los acompañan, proponen otro camino en torno a las concepciones de salud/enfermedad o de normal/patológico — retomando la demarcación de Canguilhem. 


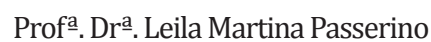
[Universidad de Buenos Aires, Argentina]

En esta dirección, las nociones de cuerpo habitual, cuerpo actual y esquema corporal, resultan fundamentales para enmarcar tales procesos en términos dinámicos, como así también apartados de una concepción basada en la localización de la enfermedad en un cuerpo reificado atemporal. Esta mirada procura una alternativa al saber del cuerpo que postula la medicina moderna, para enmarcarla dentro de una filosofía del cuerpo vivido, en la que lo normal y lo patológico adquirirán nuevos horizontes.

Como ya hemos aludido, la experiencia de la enfermedad nos pone frente a un cuerpo que parece escindirse de nuestro ser, esto es así dado que pone en evidencia las limitaciones, la experiencia motriz frente a las habitualidades del cuerpo como ser-en-el-mundo. En términos dialógicos, Canguilhem también dirá que el individuo sano no presta atención especulativa a la vida, no tiene necesidad de hacerlo, por eso para que exista una ciencia del hombre normal es precisa la experiencia de la enfermedad; “...sólo hay conciencia concreta o científica de la vida por obra de la enfermedad" (CANGUILHEM, 1966 en BATTÁN HORENSTEIN, 2008: 6). Ambos autores, entonces, dan cuenta de la demarcación normal/patológico o salud/enfermedad no en términos diferenciales taxativos, como diferencia cuantitativa, sino más bien como parte del vaivén de la existencia y regidas por una indistinción valorativa - normativa - entre estos estados (BATTÁN HORENSTEIN, 2008)³. De modo que, la salud o su recuperación, no supondría arribar a un lugar originario como "panacea", una restauración, simplemente porque aquel horizonte en el cual emergían todas nuestras relaciones habituales ha sido cuestionado y como tal ya implica una reconfiguración en el esquema corporal, que dada su sinergia, ya ha sido aprehendida. Como enuncia García, al fin y al cabo, el enfermo crónico o recuperado ha constituido un nuevo orden, una estructura total y original tan

3 Como hemos explicitado, en Merleau-Ponty, lo patológico puede ser considerado como esa puesta en evidencia de la dificultad en la habitualidad corriente. Por esto, no habría diferencia cuantitativa. Canguilhem, permite aquí introducir el carácter normativo que media tales distinciones. En una primera instancia, el autor introduce una "normatividad biológica" integrada en la vida misma que crea ciertas condiciones en las cuales la ésta será posible. La centralidad del concepto de norma se sitúa al interior del acontecimiento orgánico, es decir, la enfermedad se presenta al interior de un organismo, como experiencia global, como algo que afecta la totalidad orgánica - por sobre una desviación local. El autor, explica así que no existe un hecho normal o patológico en sí, sino que expresan otras posibles normas de vida. La normalidad proviene de la normatividad; en este aspecto, "Lo patológico no es la ausencia de norma biológica, sino una norma diferente pero que ha sido comparativamente rechazada por la vida" (CANGUILHEM, 2005: 108). El autor convierte a la enfermedad en una experiencia de innovación positiva para el ser vivo, la cual no puede ser reducida o contrapuesta al concepto de salud, sino que se presenta como nueva dimensión de la vida. Ya en 1966, esta normatividad no puede desprenderse del contexto en el cual se define y en relación a las particularidades y experiencias del individuo. Si la normatividad está en la vida, la normalidad es producto de la arbitrariedad social, refiriendo más bien al promedio o regularidad en la cual entra en juego la cuestión del a normalización. 
distinta que, según decía Merleau-Ponty, de ella no podría deducirse el estado anterior (GARCÍA, 2009: 539). En términos terapéuticos, no se trata aquí sólo de la instauración de nuevas normas vitales, sino simultáneamente ciertas modalidades con el mundo y con los otros, que transforman el cuerpo actual en cuerpo habitual, justamente en el momento en que esta incidencia tácita resulta imperceptible 4 . Y si "la adquisición de la habilidad es la captación de una significación" esto implica que la enfermedad no sólo introduce una nueva significación existencial producto de la desorganización del cuerpo vivido, sino además, reactiva otras motivaciones en el contexto subjetivo acordes con la nueva circunstancia (LÓPEZ SÁENZ, 2010: 103).

Desde una fenomenología del cuerpo vivido, podemos concluir que la enfermedad - en continuidad con la crítica de Merleau-Ponty a la ciencia moderna que tiende a definir la enfermedad mediante lo observable, verificable, localizable - tiene más que ver con un estilo de percibir la existencia, una manera de ser-en-el-mundo que supone una reorganización de nuestra vida, nuestros proyectos, nuestros hábitos y disposiciones en el mundo. Quien padece una enfermedad es alguien que está enfrentado a una dificultad, la de volver a entablar contacto con el mundo tal como lo hacía antes (BATTÁN HORENSTEIN, 2008: 5). La enfermedad deja de ser concebida como causa de la ruptura instrumental con el cuerpo material, sino será entendida como una expresión más del cuerpo vivido análogo a la pubertad, al embarazo, a la vejez, etc., que problematizan lo que antes se daba por descontado y nos obligan a reorganizarnos (LÓPEZ SÁENZ, 2010: 102).

Esta "reorganización" no necesariamente deriva en una "negatividad" o limitación de la existencia, sino que como Merleau-Ponty recuerda, muchos fenómenos pueden desempeñar el papel de reveladores, a condición de que, en lugar de ser sufridos como hechos puros que nos dominan, se conviertan en el medio de extender nuestro conocimiento (MERLEAU-PONTY, 1942: 283 en BATTÁN HORENSTEIN, 2008: 6). Parafraseando a E. García, redescubrir con Merleau-Ponty que "nadie sabe aun lo que puede un cuerpo", como rezaba Spinoza, significa recordar no sólo, por la negativa, que el cuerpo es misterioso

4 En una cita de García, podemos leer a Kurt Goldstein quien enuncia: "La salud nuevamente adquirida no es la misma de antes (...) Recuperar la salud a pesar de una secuela funcional no sucede sin una pérdida de esencia del organismo y sin la reaparición simultánea de un orden, al cual corresponde una nueva norma individual" (GOLDSTEIN, 1951: 350 en GARCÍA, 2009: 535). De aquí, que no sea una "restitución" del estado anterior, la plasticidad y sinergia del esquema corporal nos transforma de tal modo que perdemos de vista el "pasado presente" del cuerpo habitual, esto es, las disposiciones de las cuales no tenemos recuerdo, pero que aun así actúan y participan en la figuración del esquema corporal, como nuevo orden al cual no puede atribuírsele una causalidad primaria. 
y opaco a nuestra conciencia sino también, de modo positivo, la posibilidad de ver hasta qué punto son contingentes y restringidos los modos de vida que tomamos por naturales, abriendo así el espectro de nuestras posibilidades de percepción y acción (GARCÍA, 2012: 68).

Recebido em: 23.04.2018 | Aprovado em: 20.06.2018

AHO, J.; AHO, K. Body Matters. A phenomenology of sickness, disease and illness. United Kingdom: Lexington Books, 2009.

AZEVEDO, R. F., \& LOPES, R. L. M. “Concepção de corpo em Merleau-Ponty e mulheres mastectomizadas" Em: Revista Brasileira de Enfermagem, 63(6), pp. 1067-1070, 2010.

BATTÁN HORENSTEIN, A. "Entre inocencia y conocimiento: la experiencia de la enfermedad en G. Canguilhem y M. Merleau-Ponty". En: A parte Rey. Revista de Filosofía, 55, pp. 1-8, 2008.

"La centralidad de la noción de esquema corporal como quiasmo de espacio movimiento" En: Investigaciones Fenomenológicas, Nº 10, pp. 15-32, 2013.

CANGUILHEM, G. Lo normal y lo patológico. México: Siglo XXI Editores, 2005.

CROSSLEY, N. "Merleau-Ponty, the elusive body and carnal sociology". In: Body Society, 1, 43-63, 1995.

COLECLOUGH, E. M. "Hábito y corporalidad en Merleau-Ponty". En: II Congreso Internacional de Investigación y Práctica Profesional en Psicología - XVII Jornadas de Investigación Sexto Encuentro de Investigadores en Psicología del MERCOSUR.
Facultad de Psicología - Universidad de Buenos Aires, pp. 41-42, 2010.

ESPINAL PÉREZ, C. E. "El cuerpo: un modo de existencia ambiguo. Aproximación a la filosofía del cuerpo en la fenomenología de Merleau-Ponty" En: Co-herencia, Vol. 8 (15): pp. 187-217, 2011.

GARCÍA, E. "Fenomenología del cuerpo vivido y filosofía del viviente (M. Merleau-Ponty y G. Canguilhem)” En: Acta fenomenológica latinoamericana, Volumen III (Actas del IV Coloquio Latinoamericano de Fenomenología), Lima, pp. 523-538, 2009.

. Maurice Merleau-Ponty. Filosofía, corporalidad y percepción. Buenos Aires: Editorial Rhesis, 2012.

LÓPEZ SÁENZ, M. C. "Hermenéutica del cuerpo doliente-dolido desde la fenomenología del sentir" En: Investigaciones Fenomenológicas, Vol. Monográfico 2: Cuerpo y alteridad, pp. 89-123, 2010.

MERLEAU-PONTY, M. Fenomenología de la percepción, Barcelona, Planeta Agostini, 1985.

Lo visible y lo invisible, Buenos Aires, Nueva Visión, 2010.

RABELO, MCM; ALVES, PCB; SOUZA, IMA. 
Experiência de doença e narrativa, Rio de Janeiro: Editora FIOCRUZ, 1999.

RICOEUR, P. Sí mismo como otro. Madrid: Siglo Veintiuno Editores, 1996.

VALÉRY, P. Estudios filosóficos, Madrid, La balsa de la medusa, Visor, 1993.

WILDE, M. "Embodied knowledge in chronic illness and injury". In: Nursing Inquiry, 10 (3), pp. 170176, 2003. 